\title{
EDUCAÇÃO PARA DEMOCRACIA, DIREITO À PRIVACIDADE E
VIVÊNCIAS EXTENSIONISTAS EM TEMPOS DE PANDEMIA
}

\author{
Denise dos Santos Vasconcelos Silva ${ }^{1}$ \\ Letícia Santiago Farias ${ }^{2}$ \\ Nirly Vitória de Sousa Gama Carvalho ${ }^{3}$ \\ Vanessa Fernandes Monteiro ${ }^{4}$ \\ Virna Cecile Lima Duarte ${ }^{5}$
}

\section{RESUMO}

Ações de extensão universitária nas Faculdades de Direito, como o Projeto de Extensão "Socializando o Direito" da Faculdade de Direito da Universidade do Estado do Rio Grande do Norte (UERN) são instrumentos importantes para popularização das temáticas relativas aos direitos humanos, à cidadania, à democracia e à sociedade, contribuindo de forma significativa para a efetivação da educação para democracia, por exemplo, através de temas acerca dos direitos fundamentais como o direito à privacidade. A pesquisa, quanto ao tipo, utilizou análise bibliográfica, de caráter qualitativo, com natureza exploratória para demonstrar a importância de os conhecimentos acadêmicos produzidos nas Faculdades de Direito serem levados à comunidade em prol do bem-estar, da justiça social e de uma sociedade cada vez mais atuante e inclusiva.

Palavras-Chave: Educação para democracia; Extensão universitária; Cidadania; Direitos Humanos; Direito fundamental à privacidade.

Doutora em Direito pela Universidade do Porto. Mestre em Direito Constitucional pela Universidade de Lisboa. Professora da Faculdade de Direito da Universidade do Estado do Rio Grande do Norte (UERN). Pró-Reitora Adjunta de Planejamento, Orçamento e Finanças da UERN. E-mail: denisevasconcelos@ uern.br.

Graduanda do Curso de Direito na Universidade do Estado do Rio Grande do Norte (UERN). Integrante do Grupo de Estudos e Pesquisa Justiça Intergeracional e Direitos Fundamentais. Integrante do Projeto de Extensão Socializando o Direito. E-mail: leticiafarias@alu.uern.br.

Graduanda do Curso de Direito na Universidade do Estado do Rio Grande do Norte (UERN). Integrante do Projeto Socializando o Direito. E-mail: nirlycarvaçho@alu.uern.br.

Graduanda do Curso de Direito na Universidade do Estado do Rio Grande do Norte (UERN). Integrante do Projeto Socializando o Direito. E-mail: fernandesmonteiro@alu.uern.br.

Graduanda do Curso de Direito na Universidade do Estado do Rio Grande do Norte (UERN). Integrante do Projeto Socializando o Direito. E-mail: virnacecile@alu.uern.br. 


\title{
EDUCATION FOR DEMOCRACY, THE RIGHT TO PRIVACY AND EXTENSIONIST EXPERIENCES IN TIMES OF PANDEMIC
}

\begin{abstract}
University extension in Law Courses, such as the Extension Project "Socializing the Law" at the Faculty of Law of the State University of Rio Grande do Norte (UERN), constitutes an important instrument for popularizing the themes related to human rights, citizenship, democracy and society, contributing significantly to the realization of education for democracy, for example, through themes about fundamental rights such as the fundamental right to privacy. The research, in terms of type, used bibliographic analysis, of a qualitative character, with an exploratory nature to demonstrate the importance of the academic knowledge produced in Law Schools to be brought to the community in favor of well-being, social justice and a society each increasingly active and inclusive.
\end{abstract}

Keyword: Education for democracy. University Extension. Citizenship. Human rights. Fundamental right to privacy.

\section{INTRODUÇÃO}

O presente trabalho busca demonstrar que a extensão universitária nos Cursos de Direito permite ao cidadão adquirir conhecimentos sobre os direitos e deveres estabelecidos no ordenamento jurídico, de modo que através do acesso a esses conhecimentos, é possível proporcionar uma maior visibilidade para a importância da luta pelos direitos e exercício dos deveres, além de uma maior efetivação do acesso à justiça, da cidadania e da participação democrática nos espaços públicos.

Nessa conjuntura, temos que a extensão universitária, por exemplo, através de Projetos como o "Socializando o Direito" da Faculdade de Direito da Universidade do Estado do Rio Grande do Norte (UERN) populariza temáticas relativas ao Direito nas escolas, como é o caso do tema do direito à privacidade, contribuindo de forma significativa para a efetivação da educação para valores democráticos.

A extensão universitária decorre de várias disposições legislativas do nosso ordenamento jurídico como o art. 207 da Constituição Federal Brasileira (CFB), o art. 43, inciso VII da Lei n. ${ }^{\circ}$ 9.394, de 20 de dezembro 1996 - Lei de Diretrizes e Bases da Educação Nacional (LDB), o art. $3^{\circ}$ da Resolução CNE/CES n. ${ }^{\circ} 7 / 2018$, o art. $7^{\circ}$ da Resolução CNE/CES n. ${ }^{\circ}$ 5/2018, entre outros.

Visto isto, o Projeto citado oportuniza aos discentes do Curso de Direito da UERN uma formação complementar mais humana e cidadã, através da socialização dos conhecimentos apreendidos academicamente com os estudantes das escolas públicas do município de Mossoró/RN.

Ocorre que em razão das medidas de contenção do novo coronavírus (COVID-19), dentre elas o fechamento das Instituições de ensino, as atividades extensionistas do 
projeto tiveram que ser adaptadas para os ambientes virtuais, de modo que em 26 de março de 2021, foi realizada a primeira palestra do ano direcionada aos discentes do nono ano da Escola Municipal Rotary, intitulada "Direito à privacidade: avanços e desafios", a qual trabalhou temáticas como honra, imagem, intimidade, ato infracional, cyberbullying, bem como a exposição excessiva das crianças e adolescentes nas telas dos computadores, celulares e tablets, a qual pode ocasionar captação indevida de dados dos utilizadores e prejuízo à saúde mental.

A pesquisa, quanto ao tipo, utilizou análise bibliográfica, de caráter qualitativo, com natureza exploratória para demonstrar através das vivências extensionistas da Faculdade de Direito da UERN, como o "Socializando o Direito, a importância dos conhecimentos científicos produzidos na Universidade serem levados à comunidade em prol da construção de uma sociedade livre, justa e solidária; e da promoção do bem de todos, sem preconceitos de origem, raça, sexo, cor, idade e quaisquer outras formas de discriminação.

\section{EDUCAÇÃO PARA DEMOCRACIA, AÇÕES EXTENSIONISTAS E VIVÊNCIAS DO "SOCIALIZANDO O DIREITO" NO ÂMBITO DO DIREITO À PRIVACIDADE: PANORAMA GERAL}

A Lex Matter garante em seu art. 208, inciso V, o acesso em todos os níveis mais elevados do ensino, da pesquisa e da criação artística, segundo a capacidade de cada um; e em seu art. 207 assegura que as universidades gozam de autonomia didático-científica, administrativa e de gestão financeira e patrimonial, e obedecerão ao princípio de indissociabilidade entre ensino, pesquisa e extensão (BRASIL, 2020).

$\mathrm{O}$ art. 43, inciso VII da LDB, estabelece que uma das finalidades da Universidade é a promoção da extensão, aberta à sociedade, visando à difusão da pesquisa científica e tecnológica geradas na instituição (BRASIL, 1996).

O Plano Nacional de Educação (PNE), aprovado pela Lei n. ${ }^{\circ} 13.005$, de 25 de junho de 2014, com vigência de 10 (dez) anos, assegura, no mínimo, 10\% (dez por cento) do total de créditos curriculares exigidos para a graduação em programas e projetos de extensão universitária (BRASIL, 2014a).

$O$ art. $3^{\circ}$ da Resolução CNE/CES n. ${ }^{\circ} 7 / 2018$ preceitua que a extensão universitária se refere a um processo interdisciplinar, político educacional, cultural, científico, tecnológico, que promove a interação transformadora entre as instituições de ensino superior e os outros setores da sociedade (CONSELHO NACIONAL DE EDUCAÇÃO, 2018b). E o art. $7^{\circ}$ da Resolução CNE/CES n. ${ }^{\circ}$ 5/2018 (CONSELHO NACIONAL DE EDUCAÇÃO, 2018a), que instituiu as Diretrizes Curriculares Nacionais do Curso (DCNs) de Graduação em Direito, traz a importância de dar oportunidade de ações junto à comunidade ou de caráter social.

Considerando isto, o Projeto de Extensão "Socializando o Direito" da Faculdade de Direito, da Universidade do Estado do Rio Grande do Norte (UERN, [2017?]), leva para as escolas da rede pública estadual e/ou municipal, localizadas no município de Mossoró/RN, palestras acerca de temas relativos ao Direito, cidadania, educação, participação social etc. 
O referido Projeto oportuniza discentes do Curso de Direito da Faculdade de Direito da Universidade do Estado do Rio Grande do Norte uma formação humanística e proporciona a socialização dos conhecimentos apreendidos na Academia com os estudantes das escolas públicas.

Atualmente, o Projeto Socializando o Direito está em funcionamento (ref. aos semestres de 2020.1 e 2020.2), com três linhas de atuação, sendo elas: Linha 1 Direitos sociais, inclusão social e cidadania sob supervisão da Profa. Dra. Denise dos Santos Vasconcelos Silva, tendo como membros: TNS Esp. Danillo Lima da Silva, TSN Esp. Karinne Bentes, José Nilton de Oliveira Filho, Letícia Santiago Farias, Nirly Vitória de Sousa Gama Carvalho, Vanessa Fernandes Monteiro e Virna Cecile Lima Duarte; Linha 2 - Direitos Humanos das mulheres, gênero e educação sob supervisão da Profa. Me. Fernanda Abreu de Oliveira, tendo como membros: TNS Esp. Sephora Edite Nogueira do Couto Borges, Ana Beatriz Martins Tavares, Débora Felícia Silveira Cavalcante, Louise Rochelly Almeida e Moura, Mirely Amaral da Silva e Nathalia Maria Xavier Costa; e Linha 3 - Sustentabilidade, direito ambiental e políticas públicas sob supervisão da Profa. Dra. Ana Mônica Medeiros Ferreira, tendo como membros: TNS Me. Lúcia Helena Dantas, Antonio Marcelo Medeiros Nogueira, Paulo Sérgio Fernandes Silva, Raony Alves dos Santos, Renata Fernandes Bezerra de Brito e Sara de Souza Lins Batista.

Em virtude do estado de emergência global decorrente do novo coronavírus (COVID-19), as atividades extensionistas do projeto tiveram que ser adaptadas para o formato remoto através da utilização de Tecnologias da Comunicação e Informação (TICs).

Dessa forma, em 26 de março de 2021, foi realizada a palestra "Direito à privacidade: avanços e desafios" para os alunos da Escola Municipal Rotary, mais especificamente, para os discentes da turma do nono ano do ensino fundamental. A referida palestra, realizada via Google Meet, contou com 70 (setenta) participantes e tratou de diversas temáticas asseguradas constitucionalmente como privacidade, honra, imagem e intimidade.

Como o próprio nome do Projeto extensionista sugere, o objetivo das ações que são realizadas é socializar o Direito, fazendo com que várias pessoas reconheçam os direitos e deveres que possuem, bem como estimule que os indivíduos exijam, quando necessário, o asseguramento destes direitos fundamentais.

Apesar de a palestra "Direito à privacidade: avanços e desafios" ter tido como público-alvo os alunos que possuíam em torno de 13-15 anos de idade, foi possível observar que a temática atraiu bastante atenção dos adolescentes, os quais ao terem conhecimento das legislações e jurisprudências que resguardavam o direito à privacidade, compartilharam experiências e formularam inúmeras perguntas acerca do tema.

Outrossim, é válido ressaltar que também foram trazidos temas correlatos como ato infracional, nos moldes do art. $103 \mathrm{~s} / \mathrm{s}$ do Estatuto da Criança e do Adolescente (BRASIL, 1990); bullying; e cyberbullying, ambos assegurados no Programa de Combate à Intimidação Sistemática (BRASIL, 2015).

Ademais, a escolha do tema buscou sensibilizar o público-alvo acerca do 
resguardo do direito à privacidade e como a violação desse direito afeta o cotidiano dos estudantes. Dado o atual contexto de pandemia, o cuidado com a privacidade deve ser redobrado, principalmente para crianças e adolescentes, os quais podem ser alvos mais recorrentes da manipulação e prejuízo de plataformas digitais. Nesse sentido, Gigliotti expõe que como a formação total do cérebro só acontece entre os 20 e 25 anos, os jovens têm menos controle decisório e capacidade de arbitrar o que é bom e o que não é bom, tornando-se alvos perfeitos a serem explorados, por exemplo, através da captação indevida de dados dos seus usuários. Gigliotti destaca ainda que os algoritmos são imensamente utilizados como forma de "prender" os utilizadores da tecnologia, fazendo com que mais dados sejam coletados e mantendo os jovens com os olhos fixados nas telas dos computadores, celulares e tablets (GIGLIOTTI, 2020).

Destaca-se ainda o prejuízo à saúde mental causado pelo excesso de horas (6-8 horas) gastas diariamente da internet, em mídias como Instagram, Facebook, Youtube etc., as quais podem ocasionar aumento dos casos de depressão, ansiedade, suicídio, transtorno alimentar e comportamento agressivo. A título exemplificativo, nos últimos anos a procura por procedimentos estéticos tem crescido em jovens de 13 a 18 anos, motivada principalmente pela necessidade de se assemelhar com os filtros das selfies que são disponibilizados nas redes sociais (GIGLIOTTI, 2020).

Dado o exposto, é preciso ressaltar a importância da temática a nível de ensino fundamental, pois os adolescentes são as principais vítimas dos algoritmos das redes sociais, os quais visam ocupar seus usuários para coletar dados e manipular o conteúdo visto por esses, armazenando tudo em grandes bancos de informações. Outrossim, não se pode esquecer que a questão da privacidade tem ganhado muita visibilidade, principalmente pelo contexto de pandemia que trouxe a necessidade de utilização das redes em substituição ao ensino presencial. Como já apresentado, o uso indiscriminado da internet é imensamente prejudicial, mas como evitar as mídias digitais na atual conjuntura?

\section{3 (SUPER)EXPOSIÇÃO NOS ESPAÇOS VIRTUAIS: ENSINO REMOTO E UTILIZAÇÃO DE REDES SOCIAIS}

Na obra "1984" de George Orwell, a vida dos cidadãos era observada e controlada por um Estado totalitário denominado "Grande Irmão" (ORWELL, 2000). No contexto factual, a distopia de Orwell seria inconcebível, uma vez que dentre os direitos fundamentais tutelados pelo art. $5^{\circ}$ da CFB (BRASIL, 2020), encontra-se a intimidade. Esse entendimento é reforçado pela Lei n. ${ }^{\circ}$ 10.406/2002 - Código Civil (BRASIL, 2002), que assegura a vida privada da pessoa natural como inviolável. No entanto, com os avanços tecnológicos, adveio uma vulnerabilidade aos perigos do meio cibernético, que usufruem de dados dos seus usuários e manipulam o acesso a determinados conteúdos através dos algoritmos. Esses, por sua vez, atuam em busca de padrões e a partir do entendimento desse padrão, filtram as informações que melhor se adequam ao usuário. Quanto mais tempo destinado ao uso das redes, mais informações os algoritmos conseguem coletar, gerando lucro a partir da venda de dados de usuários para grandes empresas. Nesse sentido, 
[...] cada pessoa disponibiliza diariamente uma infinidade de dados que, de acordo com o avanço tecnológico, torna possível o seu tratamento, o que cria uma ferramenta valiosa no mercado de consumo. [...] Esses dados são valiosos no mercado de consumo, pois permitem o agrupamento de consumidores segundo suas preferências, facilitando o uso da publicidade, ou até mesmo determinando a possibilidade de crédito desses grupos de consumidores. Nesse contexto, a publicidade se torna cada vez mais agressiva e potencialmente danosa ao livre exercício da vontade, o que reclama proteção especial para o uso e tratamento dos dados pessoais (ALMEIDA; EVANGELISTA, 2016, p. 6).

A pesquisa TIC Kids Online Brasil, realizada em 2019 pelo Centro Regional de Estudos para o Desenvolvimento da Sociedade da Informação (CETIC), aponta que $89 \%$ da população de 9 a 17 anos é usuária de Internet no Brasil, o que equivale a 24,3 milhões de crianças e adolescentes conectados. Ademais, os dados coletados indicam que cerca de $82 \%$ utilizam as redes sociais, o que equivale aproximadamente a 22 milhões de crianças e adolescentes (CETIC, 2019). Essa realidade traz à tona a problemática, já exemplificada, que o uso excessivo da internet e das redes sociais gera prejuízo aos usuários dessa faixa etária, como depressão, ansiedade suicídio, transtorno alimentar e comportamento agressivo (GIGLIOTTI, 2020).

Uma pesquisa realizada pelo Laboratório de Projetos em Saúde Coletiva (Laprosc) da Universidade Federal do Espírito Santo (UFES), visando analisar a dependência da internet e de redes sociais, com foco no uso excessivo da internet para atividades que não sejam estudo ou trabalho e o consequente adoecimento dos jovens, realizou um questionário para analisar os fatores de riscos que jovens entre 15 e 19 anos estão sendo expostos. O questionário, aplicado entre os anos de 2016 e 2017, contava com 384 perguntas e foi aplicado a 2.293 jovens de 54 escolas de ensino médio (43 da rede pública e 11 da rede privada) dos municípios de Vitória, Vila Velha, Serra, Cariacica, Viana, Guarapari e Fundão. Os questionamentos abordavam temas como ansiedade, depressão, bullying, prática de atividades físicas, qualidade do sono, saúde bucal, autoestima, dependência da internet e acesso às redes sociais etc. (UFES, 2020).

Areferida pesquisa constatou o adoecimento do público de crianças e adolescentes como consequência da dependência da internet e das redes sociais. Dos 2.293 jovens que realizaram o questionário, 25,3\% apresentaram grau de dependência grave ou moderada. Trata-se de um problema grave, haja vista que os dependentes de internet têm $80 \%$ mais chances de desenvolver ansiedade e depressão (UFES, 2020).

Tendo como base os depoimentos de ex-executivos das maiores empresas do Vale do Silício, tais como Google, Facebook e Twitter, o documentário da Netflix intitulado "O dilema das redes", apresenta os prejuízos que as plataformas digitais trouxeram ao longo dos anos. Um dos entrevistados é Jordan Lanier, pioneiro da realidade digital, mas que na atualidade defende que as plataformas digitais estão ocasionando incontáveis malefícios para a população (O DILEMA..., 2020).

Com o intuito de auxiliar o corpo civil a compreender o uso e funcionamento da internet por crianças e adolescentes, o Instituto Alana, Educadigital e Intervozes elaboraram um guia denominado "A escola no mundo digital". No documento, é 
destacado que devido ao crescente uso das plataformas digitais, surgiu a necessidade de debater a regulação da internet, com isso, foram estabelecidos princípios éticos e orientações para promover o livre acesso e a garantia dos direitos humanos (VERNEK; MEIRA; GONSALES, 2020).

O relatório publicado, em 26 de agosto de 2020, pela Comissão Econômica para a América Latina e o Caribe (Cepal), afirma que a pandemia destacou a necessidade de legislações que assegurem o cumprimento da proteção da privacidade dos dados e criação de autoridades competentes especializadas, bem como, a importância de fortalecer o quadro institucional e marcos regulatórios no campo da privacidade de dados e a segurança cibernética é essencial (CEPAL, 2020).

No Brasil, desde 2018, a Lei Geral de Proteção de Dados Pessoais (LGPD), assegura em seu art. $1^{\circ}$ tratamento de dados pessoais, inclusive nos meios digitais, por pessoa natural ou por pessoa jurídica de direito público ou privado, com o objetivo de proteger os direitos fundamentais de liberdade e de privacidade e o livre desenvolvimento da personalidade da pessoa natural.

Ademais, a LGPD dispõe de seção específica sobre os dados pessoais de crianças e adolescentes, garantindo que a coleta e tratamento de dados deve sempre estar de acordo com o melhor interesse da criança ou adolescente, exigindo o consentimento de pelo menos um dos pais ou responsável legal (art. 14, $\S 1^{\circ}$ ), outrossim, determina que as informações sobre o tratamento de dados devem ser fornecidas de maneira simples, clara e acessível (art. 14, § $6^{\circ}$ ).

O mencionado guia também alerta que com a migração dos dados pessoais estudantis das pastas físicas para as plataformas digitais, o banco de dados que armazena essas informações fica cada vez mais recheado de informações sobre os estudantes. Ademais, dada a atual necessidade de promover o ensino com a modalidade remota, esses bancos de dados estão ainda mais alimentados. "A escola no mundo digital". também destaca que todos os trajetos de navegação feitos pelo estudante na internet, seus dados pessoais e publicações mais visualizadas, podem ser instrumentalizados para fins de exploração comercial (VERNEK; MEIRA; GONSALES, 2020).

\section{RELATO DE EXPERIÊNCIA DE UMA DAS PALESTRAS DO "SOCIALIZANDO O DIREITO”: ABRANGÊNCIAS E DESAFIOS DO DIREITO À PRIVACIDADE}

Para que as pessoas analisem a realidade vivida e saibam agir diante dela, transformando o seu cotidiano por meio do grau de consciência adquirido pela educação, é imprescindível a construção de uma consciência crítica (FREIRE, 2001), desse modo, ações extensionistas mostram-se relevantes para a realidade acadêmica e social, em especial, diante do cenário de fechamento das Instituições educacionais para contenção do novo coronavírus.

É primordial que os conhecimentos discutidos nas Faculdades de Direito ultrapassem os muros universitários e cheguem em toda coletividade, por exemplo, através de Projetos de extensão como o Projeto "Socializando o Direito", o qual realizou discussões sobre o direito à privacidade buscando debater temas como 
como honra, imagem e intimidade, mas também alertar os alunos do nono ano da Escola Municipal Rotary, em sua maioria adolescentes, para os perigos causados pelas plataformas digitais, tais como a quantidade massiva de anúncios que viabilizam exploração comercial, as quebras de segurança de dados para que sejam usadas para fins ilegais, a constante vigilância e manipulação de informações entre outros, assegurando, assim, a privacidade e a integridade dos estudantes.

\subsection{INTIMIDADE, VIDA PRIVADA, HONRA E IMAGEM: UM DEBATE NECESSÁRIO}

Incialmente analisa-se o art. $5^{\circ}$, inciso $X$ da CFB que garante a inviolabilidade da intimidade, da vida privada, da honra e da imagem das pessoas, assegurando o direito a indenização pelo dano material ou moral decorrente de sua violação (BRASIL, 2020). A intimidade é de compreensão complexa, visto que é muitas vezes confundida com a vida privada, que apesar de terem relações entre si, elas possuem especificidades. A intimidade deriva do termo em latim intimus e refere-se ao interior, ou seja, aos aspectos intrínsecos à natureza humana. Por outro lado, a vida privada relaciona-se com o particular/pessoal. Assim, "ter intimidade" seria uma qualidade que um terceiro possui perante o outro, já "ter vida privada" diz respeito ao próprio titular e não o que ele possui em relação a outrem (ARDENGHI, 2017).

É mister pontuar que a dignidade da pessoa humana é objetivo fundamental da proteção dos direitos da personalidade, nesse sentido, valores como a honra também são abrangidos constitucionalmente, a fim de proteger o cidadão de atos abusivos e possibilitar possíveis punições e indenizações provenientes desses abusos.

A honra diz respeito ao conjunto de características que evidenciam a dignidade da pessoa, por exemplo, a "boa imagem" e a "reputação". Esse conceito pode variar de acordo com aspectos temporais e espaciais. O sentido de honra pode se referir a honra objetiva ou subjetiva.

A honra objetiva se refere aos eventuais julgamentos que terceiros fazem sobre alguém, como a calúnia, que pode ser explícita, implícita ou reflexa. A difamação ocorre nos casos de divulgação de eventuais fatos ofensivos. A honra subjetiva faz referência aos juízos que determinada pessoa faz sobre si, por exemplo, em casos de injúria em que alguém atribui qualidades negativas ao outro (ARDENGHI, 2017).

Igualmente explícito na Carta Magna, tem-se o direito à imagem, caracterizandose como um dos direitos da personalidade, sendo inerente a cada indivíduo, pessoa física ou jurídica, e que, caso seja violado, gera o dever de reparação. Na legislação infraconstitucional também se verifica essa proteção no art. 20 do Código Civil (BRASIL, 2002). O direito à imagem vai além dos atributos físicos, como os traços fisionômicos, o corpo, as atitudes e os gestos. Esse direito abrange, inclusive, a transmissão sonora, ou seja, a proteção da voz de cada agente. Portanto, a imagem pode ser interpretada como extensão da personalidade exteriorizada pelo indivíduo na sociedade.

Além do art. 20 do Código Civil já citado, destaca-se a Súmula n $n^{\circ} 403$ do Supremo Tribunal de Justiça (STJ), que evidencia o dever de reparo pelo uso indevido da imagem mesmo que não haja prova do prejuízo e/ou dolo na conduta do agente (BRASIL, 2009). 
Ademais, com a expansão dos meios tecnológicos e utilização cada vez maior das redes sociais, inúmeros são os casos onde há ofensa ao direito à imagem. A título exemplificativo, seria uma situação em que o sujeito utiliza ou divulga imagens de terceira pessoa sem sua devida autorização, e há também casos mais graves, como a divulgação de fotos íntimas, onde além do dever civil de reparação, a situação pode gerar consequências na esfera criminal.

Dessa forma, a proteção do direito à privacidade passou a encarar novos desafios, especialmente com os avanços das redes sociais, com isso, fez-se necessário regular cada vez mais a internet no Brasil, por exemplo, a Lei n. ${ }^{\circ}$ 12.965/2014 veio estabelecer princípios, garantias, direitos e deveres para o uso da Internet no Brasil (BRASIL, 2014), garantindo a privacidade e a proteção de dados pessoais e também a disponibilização de dados perante ordem judicial, reforçando que o espaço virtual não é "terra sem lei". Tanto é que a partir da data em que a lei entrou em vigor, empresas que dependiam do uso de dados de navegação para as suas atividades sofreram impactos e foram capazes de vislumbrar que o direito à proteção de dados é importante e precisa ser garantido.

Ademais, $\mathrm{o}$ art. $7^{\circ}$ da Lei $n .{ }^{\circ} 12.965 / 2014$ (BRASIL, 2014) trata o acesso à internet como essencial ao exercício da cidadania, garantindo a inviolabilidade da intimidade e da vida privada, sua proteção e indenização pelo dano material ou moral decorrente de sua violação; e o art. $8^{\circ}$ da mesma Lei trata o direito à privacidade nas comunicações como condição necessária para o pleno exercício do direito de acesso à internet. Em síntese, para que os espaços digitais sejam seguros para o uso dos indivíduos e para que esses possam usufruir das vantagens que a internet oferece, é importante regular e proteger o direito à privacidade.

\subsection{ESTUDOS DE CASOS CONCRETOS COMO UMA DAS METODOLOGIAS DA AÇÃO EXTENSIONISTA DISCUTIDA}

Levando em conta que dentre as metodologias de debate, os estudos de casos concretos permitem a realização de discussões aplicadas à realidade, enfatizando os problemas sociais e as políticas públicas, de modo que se mostram bastante utilizados pelas diversas áreas do conhecimento, como o Direito e a Educação, para o incentivo ao diálogo em salas de aula, palestras ou projetos.

Nas palestras realizadas pelo projeto Socializando o Direito da UERN, como a palestra "Direito à privacidade: avanços e desafios" são utilizados casos reais com a finalidade de estimular os alunos ao debate, bem como para ratificar a importância do tema da privacidade, visto que é caracterizado como um impasse nos dias atuais.

Casos como o da biografia não autorizada da cantora Anitta, visto que é uma artista que vem fazendo bastante sucesso no Brasil e no exterior. Tal biografia foi intitulada como "Furacão Anitta", sendo produzida pelo jornalista Léo Dias. A referida biografia não teve consentimento da artista. Além disso, o relato trazia inúmeros fatos polêmicos de sua vida pessoal, tais como alguns desentendimentos familiares, o seu casamento inesperado e conflitos com outros artistas, em que a mesma já chegou a fazer parcerias. 
É importante salientar que a Constituição Brasileira trata o direito à privacidade, à honra, à informação e às liberdades de expressão como direitos fundamentais, não estabelecendo qualquer hierarquia entre eles, estando dispostos nos art. $5^{\circ}$, incisos $\mathrm{X}$ eIX.

Nesse cenário, como os direitos fundamentais são mandamentos de otimização e deverão ser vistos sob a ótica de uma teoria de suporte fático amplo, os quais devem ser realizados na maior medida possível, dificilmente as suas concretizações não encontrariam barreiras na proteção de outro(s) princípio(s), por isso uma eventual colisão entre princípios seria resolvida no plano da eficácia, aplicando a ponderação (e o uso da proporcionalidade) (ALEXY, 2011, p. $90 \mathrm{~s} / \mathrm{s}$ ).

Um dos casos analisados foi a ADI/DF n. ${ }^{\circ} 4.815$, em que o Supremo Tribunal Federal (STF) firmou entendimento acerca da inexigibilidade de autorização prévia para a publicação de biografias. A Ministra Cármen Lúcia, relatora da ação, considerou inexigível a autorização do biografado para a publicação de biografias. Para a Ministra, "a norma infraconstitucional não pode amesquinhar preceitos constitucionais impondo restrições ao exercício de liberdades" (BRASIL, 2016, p. 25). Entretanto, a relatora pontuou que condenar alguém que busca o Judiciário em defesa de sua privacidade é também uma forma de censura. E, caso tenham violações, haverá uma reparação.

No âmbito do Superior Tribunal de Justiça (STJ), atenuou-se o direito à imagem em situações voltadas ao interesse geral como fins didáticos, científicos e jornalístico em espaços públicos, em especial, quando tratam-se de pessoas que exerçam atividades públicas ou famosas, sempre se vedando o abuso (BRASIL, 2017). Outro caso interessante envolvendo o tema, trata-se da discussão acerca de eventual configuração de dano moral pelo uso, em campanha publicitária de automóvel, de uma imagem de um torcedor que estava no estádio assistindo uma partida de futebol do seu time. Ao apreciar esse caso, o STJ entendeu que a publicidade discutida estava inserida em um contexto de torcida e não a individualização da imagem do torcedor, de modo que não há que falar em violação à imagem, se não configurada a projeção, identificação e singularização do indivíduo (BRASIL, 2017a).

Também foi trazida a Lei n. $^{\circ} 12.737 / 2012$, conhecida como Lei Carolina Dieckmann (BRASIL, 2012), a qual é voltada para crimes virtuais e delitos informáticos e acrescenta os arts. 154- A e 154- B, alterando a redação dos arts. 266 e 298 do Código Penal (BRASIL, 1940). Sua redação prevê que os crimes que ocorrem através de uso de informação e materiais pessoais sem consentimento, dizem respeito à privacidade da pessoa. É mister pontuar que a Lei n. ${ }^{\circ} 12.737 / 2012$ foi o primeiro texto a tipificar os crimes cibernéticos, tendo como foco as invasões de dispositivos que ocorrem sem a autorização do proprietário. Recebeu esse nome, pois foi a partir do caso da atriz Carolina Dieckmann, visualizou-se a necessidade da tipificação desses crimes virtuais. A artista teve seu computador invadido por um hacker, o qual teve acesso a mais de 30 fotos íntimas dela, exigindo uma determinada quantia para que ele, o criminoso virtual, não as divulgasse nas redes sociais.

Ademais, o tema do cyberbullying também foi abordado, o qual se configura como a prática de intimidação, humilhação, exposição vexatória, perseguição, calúnia e difamação por meio de ambientes virtuais, como redes sociais, e-mail e aplicativos 
de mensagens. Para isso, foram utilizados casos práticos de conhecimento nacional protagonizados por pessoas notórias, e também casos de pessoas anônimas, que, por envolverem um assunto tão sensível como o cyberbullying, tomaram proporções gigantescas.

Nesse sentido, a título exemplificativo, foi exposta uma publicação da atriz Bruna Marquezine postada em sua conta pessoal do Instagram (@brunamarquezine). Tal publicação explicitava uma fotografia da atriz com trajes de banho e continha inúmeros comentários criticando a sua aparência física, como "magrelinha sem graça", "emagreceu demais", "puro osso", "você é linda demais para ficar tão magra", entre outros. De forma análoga, também foi trazida uma publicação do Instagram (@pretagil) da cantora Preta Gil com trajes de banho, tendo sido igualmente alvo de críticas ao seu corpo, por exemplo, “Jesus!!!", “Enorme”, "Misericórdia” etc. Na pesquisa feita das duas imagens citadas, observou-se que os perfis que faziam tais comentários eram perfis, em sua maioria, verdadeiros, mas também havia frases advindas dos chamados "perfis fakes" (INSTAGRAM, [200-?]).

Após isso, foi a vez de exemplificar a notícia que abordava as críticas que a cantora Anitta vinha sofrendo após seguir uma amiga que expôs a opinião política no Instagram. A cantora, inclusive, chegou a usar o termo cyberbullying para explicar os xingamentos, ameaças e massacres que vinha sendo alvo (VOGUE, 2018).

Vale ressaltar que no âmbito brasileiro, o Programa de Combate à Intimidação Sistemática preceitua que há intimidação sistemática na rede mundial de computadores (cyberbullying), quando se usarem os instrumentos que lhe são próprios para depreciar, incitar a violência, adulterar fotos e dados pessoais com o intuito de criar meios de constrangimento psicossocial (BRASIL, 2015).

Tal intimidação sistemática pode ser classificada como verbal (insultar, xingar e apelidar pejorativamente), moral (difamar e caluniar), sexual (assediar e abusar), social (isolar e excluir), psicológica (perseguir, amedrontar, chantagear e infernizar), física (socar, chutar e bater), material (furtar ou destruir pertences) e virtual (depreciar, enviar mensagens intrusivas da intimidade, enviar ou adulterar fotos e dados pessoais que resultem em sofrimento ou com o intuito de criar meios de constrangimento psicológico e social). Por isso a importância de mostrar que cyberbullying é um assunto sério e merece atenção dos adolescentes e adultos, tanto é que já houve casos trágicos, como o de uma menina de 15 (quinze) anos que praticou suicídio por sofrer cyberbullying por longos 3 (três) anos, passando por agressões, xingamentos e julgamentos por seus colegas na escola, e o principal meio utilizado para tais atos foi o Facebook (MARQUES, 2012).

Por fim, percebe-se que os conhecimentos discutidos nas Faculdades de Direito e levados aos alunos de escola pública no Projeto de Extensão "Socializando o Direito" são primordiais para realidade acadêmica e social, pois permite que o público-alvo tenha conhecimento de assuntos legislativos e jurisprudenciais ligados aos direitos humanos; analise criticamente a realidade vivida e saiba agir diante dela; ressignifique o cotidiano por meio do grau de consciência adquirido pela educação em prol dos direitos fundamentais, como o direito à privacidade; busque a construção de uma sociedade efetivamente livre, justa e solidária; e atue na promoção do bem de todos, 
sem preconceitos de origem, raça, sexo, cor, idade e quaisquer outras formas de discriminação.

\section{SÍNTESE CONCLUSIVA}

A extensão universitária nas Faculdades de Direito permite a apreensão dos conteúdos jurídicos, da interlocução com a prática e do diálogo entre ensino/pesquisa/ extensão de temas como direitos, garantias e deveres fundamentais presentes no ordenamento jurídico, possibilitando, ainda, que esses conhecimentos sejam externados ao público externo, visto que a sociedade é composta de diversos grupos sociais, os quais devem compreender seu papel como cidadão.

Considerando isto, o Projeto de Extensão da Faculdade de Direito da UERN intitulado "Socializando o Direito" - Linha 1 - Direitos sociais, inclusão social e cidadania escolheu abordar o direito à privacidade em uma das suas ações, objetivando contribuir para a pesquisa e o estudo da temática ao transmitir, para os alunos do nono ano da Escola Municipal Rotary, conceitos como intimidade, vida privada, honra e imagem, bem como, contemplando exemplos práticos das temáticas. Vale ressaltar que o público-alvo da referida ação faz parte da parcela da população mais antenada à internet $\mathrm{e}$, consequentemente, os que mais podem sofrer abusos de dados.

Diante do exposto, a proteção à dignidade da pessoa humana é objetivo essencial dos direitos da personalidade, o qual liga-se diretamente com o direito à privacidade, presente no art. $5^{\circ}$, inciso $X$ da CFB, o qual assegura inclusive o direito à indenização pelo dano material ou moral decorrente de violações relacionadas à intimidade, à vida privada, à honra ou à imagem das pessoas. Desse modo, foi exemplificado, por meio de caso concretos, pessoas que tiveram sua privacidade violada, como o caso da cantora Anitta, alvo de uma biografia não autorizada, ou ainda, da atriz Carolina Dieckmann, que teve fotos íntimas hackeadas e divulgadas, tal fato, de grande repercussão, nomeou a Lei n. ${ }^{\circ} 12.737 / 2012$ como Lei Carolina Dieckmann. A referida Lei tem como finalidade regular condutas no ambiente digital, principalmente aquelas relacionadas à invasão de privacidade (BRASIL, 2012).

As regulamentações no âmbito da internet não pararam em 2012, pois a Lei n. ${ }^{0}$ 12.965/2014 (BRASIL, 2014) estabeleceu princípios, garantias, direitos e deveres para o uso da Internet no Brasil., a fim de garantir a inviolabilidade da intimidade e da vida privada no ciberespaço; a Lei n. ${ }^{\circ} 13.185 / 2015$ afirmou que há intimidação sistemática na rede mundial de computadores (cyberbullying) quando se usarem os instrumentos que lhe são próprios para depreciar, incitar a violência, adulterar fotos e dados pessoais com o intuito de criar meios de constrangimento psicossocial; a Lei n. ${ }^{\circ} 13.709 / 2018$ (BRASIL, 2018) veio dispor sobre o tratamento de dados pessoais, inclusive nos meios digitais, por pessoa natural ou por pessoa jurídica de direito público ou privado, com o objetivo de proteger os direitos fundamentais de liberdade e de privacidade e o livre desenvolvimento da personalidade da pessoa natural; a Lei n. ${ }^{\circ} 13.853 / 2019$ (BRASIL, 2019) alterou a Lei n. ${ }^{\circ} 13.709 / 2018$ para dispor sobre a proteção de dados pessoais e para criar a Autoridade Nacional de Proteção de Dados etc. Visto isto, percebe-se que os avanços tecnológicos propiciaram novas formas 
de violar a privacidade das pessoas, isso gerou verdadeiros desafios na proteção à intimidade dos usuários, surgindo a necessidade de regular cada vez mais o uso das redes.

A referida Palestra também chamou atenção para o prejuízo à saúde mental causado pelo excesso de horas dispendidas diariamente na internet, as quais podem ocasionar depressão, ansiedade suicídio, transtorno alimentar e comportamento agressivo. Não se pode esquecer ainda que em razão da pandemia ocorreu maior intensificação da utilização das plataformas digitais, por exemplo, por conta do home office e do ensino remoto. A temática mostrou-se ainda mais pertinente, pois os adolescentes mostram-se mais vulneráveis aos algoritmos das redes sociais, que visam ocupar seus usuários para coletar dados e manipular o conteúdo visto por esses, armazenando tudo em grandes bancos de informações. Por isso, a relevância acadêmica e social de aprofundar os referidos temas.

Por fim, o 'Estado de bem-estar digital', deve rejeitar a coleta não autorizada e o uso indevido ou não autorizado de dados, bem como proporcionar elevados padrões de segurança da informação e evitar qualquer tipo de violação da privacidade e da dignidade da pessoa humana (CEPAL, 2020). Outrossim, os Cursos de Direito deverão estimular cada vez mais a realização de atividades curriculares de extensão e de aproximação profissional que articulem o aprimoramento e a inovação de vivências relativas ao campo de formação através de ações junto à comunidade e de caráter social, como clínicas e projetos, não só pela obrigatoriedade trazida no art. $7^{\circ}$ da Resolução CNE/CES n. ${ }^{\circ}$ 5/2018 mas em prol de uma formação do futuro profissional do Direito mais humana, reflexiva e crítica.

\section{REFERÊNCIAS}

ALMEIDA, Juliana; EVANGELISTA, Daniel. A ditadura do algoritmo e a proteção da pessoa humana: Uma análise do controle do Si eletrônico. Revista de Direito Privado, v. 69, set., 2016. Disponível em: http://www.mpsp.mp.br/portal/page/portal/ documentacao e divulgacao/doc biblioteca/bibli_servicos produtos/bibli boletim/ bibli bol 2006/RDPriv n.69.02.PDF. Acesso em: 30 mar. 2021.

ARDENGHI, Régis Schneider. Os direitos da personalidade: vida privada, intimidade, segredo, honra e imagem na legislação brasileira. Unisul de Fato e de Direito: Revista jurídica da Universidade do Sul de Santa Catarina, v. 8, n. 15, p. 59-68, 2017.

BRASIL. Decreto-Lei n 2.848, de 7 de dezembro de 1940. Código Penal. Rio de Janeiro: Presidência da República, 1940. Disponível em: http://www.planalto.gov.br/ ccivil_03/decreto-lei/del2848compilado.htm. Acesso em: 10 abr. 2021. 
BRASIL. Lei $\mathbf{n}^{\circ} \mathbf{8 . 0 6 9}$, de 13 de julho de 1990. Dispõe sobre o Estatuto da Criança e do Adolescente e dá outras providências. Brasília: Presidência da República, 1990. Disponível em: http://www. planalto.gov.br/ccivil 03/leis//8069.htm. Acesso em: 10 abr. 2021.

BRASIL. Lei $\mathbf{n}^{\circ}$ 9.394, de 20 de dezembro de 1996. Estabelece as diretrizes e bases da educação nacional. Brasília: Presidência da República, 1996. Disponível em: http://www.planalto.gov.br/ccivil 03/leis//9394.htm. Acesso em: 17 mar. 2021.

BRASIL. Constituição da República Federativa do Brasil: texto constitucional promulgado em 5 de outubro de 1988, compilado até a Emenda Constitucional $\mathrm{n}^{\circ}$ 106/2020. Brasília: Senado Federal; Coordenação de Edições Técnicas, 2020.

BRASIL. Lei $\mathbf{n}^{\circ} \mathbf{1 0 . 4 0 6}$, de 10 de janeiro de 2002. Institui o Código Civil. Brasília: Presidência da República, 2002. Disponível em: http://www.planalto.gov.br/ ccivil 03/ ato2011-2014/2014/lei/12965.htm. Acesso em: 04 abr. 2021.

BRASIL. Superior Tribunal de Justiça. Súmula $\mathbf{N}^{\circ}$ 403. Independe de prova do prejuízo a indenização pela publicação não autorizada de imagem de pessoa com fins econômicos ou comerciais. Brasília: STJ, 2009. Disponível em: https://www.stj. jus.br/docs internet/revista/eletronica/stj-revista-sumulas-2014 38 capSumula403. pdf. Acesso em: 17 mar. 2021.

BRASIL. Lei $\mathbf{n}^{\mathbf{0}} \mathbf{1 2 . 7 3 7}$, de $\mathbf{3 0}$ de novembro de 2012. Dispõe sobre a tipificação criminal de delitos informáticos; altera o Decreto-Lei $n^{\circ} 2.848$, de 7 de dezembro de 1940 - Código Penal; e dá outras providências. Brasília: Presidência da República, 2012. Disponível em: http://www.planalto.gov.br/ccivil 03/ ato2011-2014/2012/lei/ 112737.htm. Acesso em: 17 mar. 2021.

BRASIL. Lei $n^{\circ}$ 12.965, de 23 de abril de 2014. Estabelece princípios, garantias, direitos e deveres para o uso da Internet no Brasil. Brasília: Presidência da República, 2014. Disponível em: http://www.planalto.gov.br/ccivil 03/ ato20112014/2014/lei/l12965.htm. Acesso em: 17 mar. 2021.

BRASIL. Lei $\mathbf{n}^{\circ} \mathbf{1 3 . 0 0 5}$, de 25 de junho de 2014. Aprova o Plano Nacional de Educação - PNE e dá outras providências. Brasília: Presidência da República, 2014a. Disponível em: http://www.planalto.gov.br/ccivil 03/ ato2011-2014/2014/lei/ 113005.htm. Acesso em: 17 mar. 2021.

BRASIL. Lei $\mathbf{n}^{0} \mathbf{1 3 . 1 8 5 , 6}$ de novembro de 2015. Institui o Programa de Combate à Intimidação Sistemática (Bullying). Brasília: Presidência da República, 2015.

Disponível em: http://www. planalto.gov.br/ccivil 03/ ato2015-2018/2015/lei/l13185. htm. Acesso em: 10 abr. 2021. 
BRASIL. Supremo Tribunal Federal. Ação Direta de Inconstitucionalidade No 4.815, Distrito Federal. Ação Direta de Inconstitucionalidade. Arts. 20 e 21 da Lei n. 10.406/2002 (Código Civil) [...]. Relatora: Min. Cármen Lúcia, 10 de junho de 2015. Brasília: STF, 2016.

BRASIL. Superior Tribunal de Justiça(4. Turma). Recurso Especial No 1.594.865. Responsabilidade Civil. Publicação de imagem de atriz famosa em sítio eletrônico [...]. Relator: Min. Luiz Felipe Salomão, 18 de junho de 2017. Brasília: STJ, 2017.

BRASIL. Superior Tribunal de Justiça (3. Turma). Recurso Especial No 1.772.593RS. Recurso Especial. Ação de Compensação de Dano Moral. Julgamento CPC/15. Relatora: Min. Nancy Andrighi, 18 de setembro de 2017. Brasília: STJ, 2017a.

BRASIL. Lei n 13.709, de 14 de agosto de 2018. Lei Geral de Proteção de Dados Pessoais (LGPD). Brasília: Presidência da República, 2018. Disponível em: http:// www.planalto.gov.br/ccivil 03/ ato2015-2018/2018/lei/l13709.htm. Acesso em: 17 mar. 2021.

BRASIL. Lei n $^{0}$ 13.853, de 8 de julho de 2019. Altera a Lei $n^{0} 13.709$, de 14 de agosto de 2018, para dispor sobre a proteção de dados pessoais e para criar a Autoridade Nacional de Proteção de Dados; e dá outras providências. Brasília: Presidência da República, 2019. Disponível em: http://www.planalto.gov.br/ ccivil 03/ Ato2019-2022/2019/Lei/L13853.htm\#art1. Acesso em: 17 mar. 2021.

CEPAL. Universalizar el acceso a las tecnologías digitales para enfrentar los efectos del COVID-19. 2020. Disponível em: https://www.cepal.org/es/ publicaciones/45938-universalizar-acceso-tecnologias-digitales-enfrentar-efectoscovid-19. Acesso em: 02 abr. 2021.

CETIC. Pesquisa TIC Kids Online Brasil. 2019. Disponível em: https://cetic. br/media/docs/publicacoes/2/20201123093441/resumo executivo tic kids online 2019.pdf. Acesso em: 28 mar. 2021.

CONSELHO NACIONAL DE EDUCAÇÃO. Resolução № 5, de 17 de dezembro de 2018. Institui as Diretrizes Curriculares Nacionais do Curso de Graduação em Direito e dá outras providências. Brasília: Ministério da Educação, 2018a. Disponível em: http://portal.mec.gov.br/index.php?option=com docman\&view=download\&ali as=104111-rces005-18\&category slug=dezembro-2018-pdf\&ltemid=30192. Acesso em: 17 mar. 2021. 
CONSELHO NACIONAL DE EDUCAÇÃO. Resolução $\mathbf{N}^{\circ}$ 7, de 18 de dezembro de 2018. Estabelece as Diretrizes para a Extensão na Educação Superior Brasileira e regimenta o disposto na Meta 12.7 da Lei no 13.005/2014, que aprova o Plano Nacional de Educação - PNE 2014-2024 e dá outras providências. Brasília: Ministério da Educação, 2018b. Disponível em: http://portal.mec.gov.br/index. php?option=com docman\&view=download\&alias=104251-rces007-18\&category slug=dezembro-2018-pdf\&ltemid=30192. Acesso em: 17 mar. 2021.

FREIRE, Paulo. Educação e atualidade brasileira. São Paulo: Cortez, 2001.

GIGLIOTTI, Analice. Como as redes sociais estão adoecendo os jovens?. 2020. Disponível em: https://vejario.abril.com.br/blog/manual-de-sobrevivencia-noseculo-21/redes-sociais-adoecendo-jovens/. Acesso em: 30 mar. 2021.

INSTAGRAM. Feed. [200-?]. Disponível em: https://www.instagram.com/. Acesso em: 04 abr. 2021.

MARQUES, Melissa. Entenda o caso de Amanda Todd, a adolescente que cometeu suicídio por sofrer bullying. 2012. Disponível em: https://todateen.uol. com.br//amanda-todd-suicidio-por-sofrer-bullying/. Acesso em: 01 abr. 2021.

O DILEMA das redes. Direção: Jeff Orlowski. Produção: Larissa Rhodes. Estados Unidos: Netflix, 2020. Disponível em: https://www.netflix.com/br/title/81254224. Acesso em: 11 abr. 2021

ORWELL, George. 1984. 24.ed. São Paulo: Companhia Editora Nacional, 2000. Disponível em: https://lelivros.love/book/baixar-livro-1984-george-orwell-em-pdfepub-e-mobi-ou-ler-onlinel. Acesso em: 04 abr. 2021.

SILVEIRA, Sérgio Amadeu da. Democracia e os códigos invisíveis: como os algoritmos estão modulando comportamentos e escolhas políticas. São Paulo: SESCSP, 2019. Disponível em: https://books.google.com.br/books?hl=pt-BR\&lr=\&id =Wb2ZDwAAQBAJ\&oi=fnd \&pg=PT3\&dq=manipula $\% \mathrm{C} 3 \% \mathrm{~A} 7 \% \mathrm{C} 3 \% \mathrm{~A} 3 \mathrm{o}+$ algoritmos \&ots= EB knrW2J\&sig=SLEeU89EEHZXn-iwMb72svMi2-U\#v=onepage\&q\&f=false. Acesso em: 28 mar. 2021.

UERN. Projeto de Extensão Socializando o Direito. [2017?]. Disponível em: http:// fad.uern.br/default.asp?item=fad\%20-\%20socializando\%200\%20direito. Acesso em: 17 mar. 2021.

UFES. Pesquisa levanta fatores de risco para jovens entre 15 e 19 anos da Grande Vitória. 2020. Disponível em: https://www.ufes.br/conteudo/pesquisalevanta-fatores-de-risco-para-jovens-entre-15-e-19-anos-da-grande-vitoria. Acesso em 10 abr. 2021 
VERNEK, lago; MEIRA, Marina; GONSALES, Priscila. A Escola no mundo digital - dados e direitos de estudantes. 2020. Disponível em: https://www.cartacapital. com.br/blogs/intervozes/a-escola-no-mundo-digital-dados-e-direitos-de-estudantes/. Acesso em: 31 mar. 2021

STVOGUE. Anitta recebe ataques na internet e desabafa: "estou me sentindo muito desrespeitada". 2018. Disponível em: https://vogue.globo.com/moda/gente/ noticia/2018/09/anitta-recebe-ataques-na-internet-e-desabafa.html. Acesso em: 01 abr. 2021. 